\title{
Muito Além do Jardim: um filme e algumas reflexões sobre transformações tecnológicas e antropogenética
}

Maria Ignês Carlos Magno

Doutora em Ciências da Comunicação pela ECA/USP.

Professora da Universidade Anhembi Morumbi e da Fundação Escola de Sociologia e Política de São Paulo.

E-mail: unsigster@gmail.com

\begin{abstract}
A televisão está produzindo uma espécie de permutação, uma metamorfose, que atinge a própria natureza do homo sapiens. É por isso que a televisão não é somente um instrumento de comunicação; é ao mesmo tempo também Paidéia, um instrumento "antropogenético", um medium (meio) que gera um novo anthropos, um novo tipo de ser humano ${ }^{1}$.
\end{abstract}

Quando pensamos nos avanços tecnológicos que nos colocaram na chamada era da cibernética; quando percebemos que mais nada ou quase nada nos provoca estranhamento e até aguardamos com certa ansiedade a próxima novidade nas convergências das mídias; quando ouvimos que hoje os conhecimentos se dão em forma de rizomas e que as pesquisas virtuais proporcionam desde uma outra forma de arte até as experiências das realidades ampliadas (RA) que vêm sendo desenvolvidas nos diferentes campos da atividade humana; quando acessamos a internet e navegamos do e-mail a textos, shows, filmes, músicas, arte, podemos questionar o significado da televisão nos dias atuais.
1. SARTORI, Giovanni. Homo Videns. Televisão e pós-pensamento. Bauru: Edusc, 2001. p. 23. 
E podemos questionar ainda mais: por que trazer a TV para a sala dos professores e propor uma discussão sobre as transformações tecnológicas e a antropogenética? Ou por que escolher o filme Muito Além do Jardim como ponto de partida para leituras e reflexões sobre TV e as transformações do homo sapiens? Talvez porque a TV, ao ser substituída pelo computador, deixou de aparecer como um dos principais focos de nossas críticas em relação às atitudes e ao desinteresse dos alunos em sala de aula; e, principalmente, porque a televisão é parte essencial de uma das reflexões teóricas do momento sobre as transformações ocorridas na natureza do ser humano.

Giovanni Sartori, por exemplo, ao discutir o processo revolucionário dos meios de comunicação com seus muitos tentáculos (internet, computadores pessoais, espaço cibernético etc.), e ter a televisão como foco principal de análise, afirma que "o vídeo está transformando o homo sapiens produzido pela cultura escrita em homo videns, na qual a palavra vem sendo destronada pela imagem"”. Para Edmond Couchot: "A estruturação da tela em pontos elementares lhe dá, como McLuhan o demonstrou, um caráter de mosaico, exigindo do olho um trabalho de recomposição sintética e uma focalização diferente daquela imposta pela leitura ou a visão em alta definição do cinema”’.

Quanto à segunda questão, a escolha se deu porque o filme Muito Além do Jardim é uma adaptação do romance Being There, de Jerzy Kosinski, escrito em 1971. Em 1979, foi roteirizado pelo próprio autor e transformado em filme. No Brasil, o título do romance é Vidiota, e o do filme, Muito Além do Jardim, particularmente interessante, porque é exemplar para ilustrar a reflexão proposta.

\section{FICHA TÉCNICA}

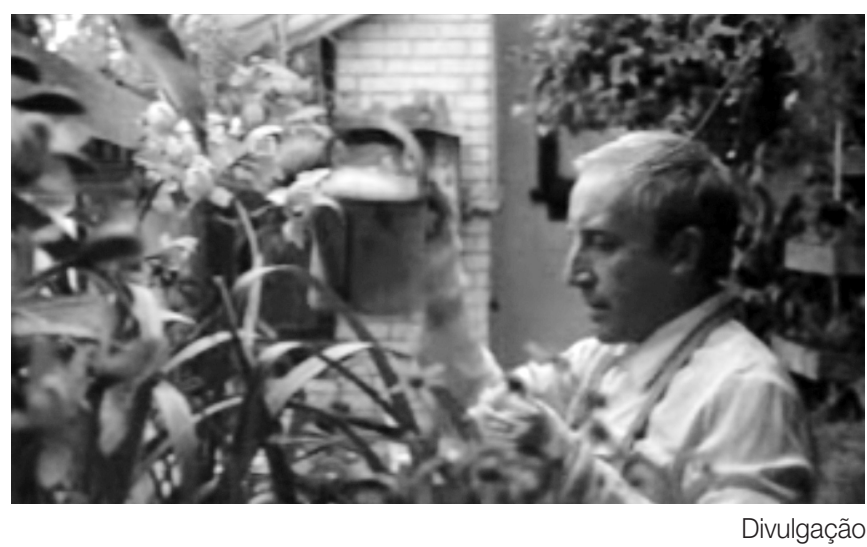

Muito Além do Jardim

2. Ibid., p. 7-8

3. COUCHOT, Edmond. A tecnologia na arte: da fotografia à realidade virtual. Porto Alegre: Editora da UFRGS, 2003. p. 85
Título original: Being There

Gênero: Comédia

Tempo de duração: 130 minutos

Ano de lançamento (EUA): 1979

Estúdio: BSB/CIP/Enigma/Fujisankei/Lorimar Film Entertainment/NatWest

Ventures/Northstar 
Distribuição: United Artists/Warner Bros.

Direção: Hal Ashby

Roteiro: Jerzy Kosinski

Produção: Andrew Braunsberg

Música: Johnny Mandel

Fotografia: Caleb Deschanel

Desenho de produção: Michael D. Haller

Figurino: May Routh

Edição: Don Zimmerman

O filme conta a história de Chance - trocadilho em inglês que significa acaso -, um órfão e analfabeto que viveu quase toda sua vida como jardineiro de uma mansão e que nunca havia deixado a casa onde vivia. Após a morte de seu patrão, é obrigado a enfrentar o mundo fora dos muros que cercam seu jardim. Chance era um homem ingênuo que, além de cuidar do jardim, via televisão, seu único contato com o mundo. Ele nunca havia entrado em um carro, não sabia ler nem escrever, não tinha carteira de identidade; resumindo: não existia oficialmente. Ele é acidentalmente atropelado pelo automóvel de Benjamin Rand, um grande magnata que se torna seu amigo. Curiosamente, tudo o que é dito por Chance ou até mesmo o seu silêncio é considerado genial.

Como a proposta inicial é refletir sobre as transformações e mudanças que as tecnologias têm produzido no homo sapiens, acredito ser interessante trazer a televisão - que consiste, como o próprio nome diz, em ver de longe (tele-ver) - como ponto de partida para as discussões, bem como as diferentes leituras e estudos sobre a TV e sobre as mutações antropológicas que estamos vivendo desde o início da modernidade.

Para discutirmos o filme e a problemática que ele traz, é interessante conhecermos as análises de alguns teóricos sobre a televisão. No caso, citarei dois deles: Giovanni Sartori e Edmond Couchot. O primeiro é um dos mais críticos estudiosos da televisão no momento. É dele a tese de que, com o advento da televisão, ocorreu uma ruptura no sistema de comunicação humana, porque o homem passou a ser mais um animal vidente do que simbólico. Embora concorde com Habermas sobre os efeitos maléficos da TV, diz que precisamos entender que ela está mudando a natureza humana, pois, entre outras situações, estamos vivendo em um mundo que já se apóia nos "ombros de uma geração televisiva - uma espécie recentíssima de ser humano criado pela tele-visão-, diante de um televisor antes mesmo de saber ler e escrever"4. E o predomínio do visível sobre o inteligível conduz para um ver sem entender.

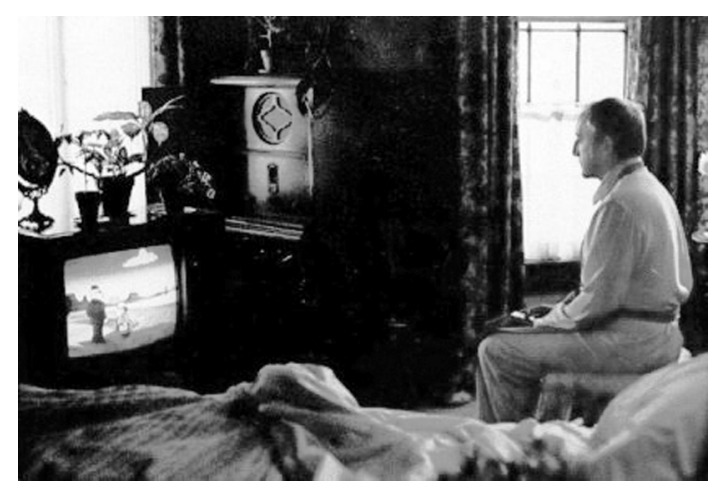

Divulgação
4. SARTORI, op. cit., p. 8. 
O personagem Chance pode ser discutido como um filho da geração televisiva. É analfabeto, desconhece a escrita e a leitura. Sua vida é ditada pela tela da TV, e vive o tempo presente. Não tem passado, não tem memória. Suas lembranças são as imagens vistas pela telinha.

Chance não questiona, não reflete, apenas repete. Todas as respostas dadas às pessoas são trechos de falas de personagens televisivos. Sua voz é secundária, porque está a serviço e em função da imagem. Seguindo as análises de Sartori, tal personagem simboliza o que o autor considera a ruptura na comunicação humana, porque se era a capacidade simbólica que distanciava o homo sapiens dos outros animais, o predomínio da visão o aproxima de novo às suas capacidades ancestrais. Aspecto que merece uma explicação para alimentar o debate.

Sartori apóia uma de suas reflexões sobre as mutações do homo sapiens em homo videns nos estudos de Ernest Cassirer (1948). Para discutir o que chamou em seu texto de a primazia da imagem sobre a palavra, Sartori - após explicar que a expressão homo sapiens foi usada pela primeira vez em 1758 por Lineu, em sua obra Sistema da Natureza, em que dizia que, do ponto de vista fisiológico, o homo sapiens não tinha nada que o tornasse único entre os primatas, exceto sua capacidade simbólica - retoma o texto de Cassirer e expõe o que o levou a definir o ser humano como "animal simbólico". Segundo Cassirer, citado por Sartori (p. 11):

O homem não vive dentro de um universo puramente físico, mas sim um universo simbólico. Língua, mito, arte e religião [...] são os vários fios que compõem o tecido simbólico [...]. Qualquer progresso humano no pensamento e na experiência fortalece este tecido [...]. A definição do homem como animal racional não perdeu nada de seu valor [...], mas é fácil perceber que tal definição é uma parte de um todo. Pois lado a lado com a linguagem conceitual há uma linguagem do sentimento, lado a lado com a linguagem lógica ou científica existe a linguagem da imaginação poética. De início a linguagem não exprime pensamentos ou idéias, mas sentimentos e afetos ${ }^{5}$.

Se retomarmos o filme e a personagem, vemos que Chance não demonstra nenhum sentimento ou afeto pelas pessoas. Paradoxalmente, seu deslocamento do chamado mundo real provoca a simpatia das pessoas para com ele, uma vez que transmite sua ingenuidade e sinceridade perante o mundo. Responde aos estímulos externos apenas quando estes se identificam com as imagens e falas dos personagens televisivos. Sua realidade está dentro da tela de TV. Chance fala, mas não questiona, não pensa nem reflete sobre o que diz, o que nos leva a um outro ponto da discussão: a do homem como um animal loquax, o qual, além de falar, está "constantemente em diálogo consigo mesmo"6. Nas análises de Sartori, "pode-se dizer que esta é a característica que o distingue radicalmente de qualquer outra espécie de ser vivo [...]. O homem reflete sobre o que diz. A linguagem não é só um instrumento para ele se comunicar, mas também para pensar"7.

Mas Chance, personagem criada e duplamente ficcionada por Jerzy Kosinski, também nos possibilita outras reflexões sobre a tele-visão, além das discutidas por Sartori. 
Sabemos que Chance nunca havia saído dos jardins da mansão onde viveu desde criança. No entanto, na seqüência em que o avisam de que precisaria deixar a casa e sair para o mundo exterior, o que percebemos é a familiaridade com a realidade real, a vivida fora da tela da TV. A única surpresa é poder ver sua própria imagem dentro da TV, quando se encontra diante de uma loja em que é filmado. Inversão interessante, se pensarmos também que o aprendizado obtido pelas imagens e textos televisivos são os elementos que o colocam em sintonia com a vida real e permitem que ele sobreviva, mesmo que na ficção.

De qualquer forma, o debate pede outras leituras e visões sobre as transformações tecnológicas e as mudanças que se processam na antropologia humana, em geral, e sobre a televisão, em particular. Enquanto Sartori analisa a chegada da TV como ponto de ruptura no sistema de comunicação lingüística - porque, enquanto todos os meios de comunicação de massa, inclusive o rádio, que, mesmo tendo o predomínio da fala, divulga sempre o expresso em palavras, a TV desloca a comunicação do contexto da fala para o da imagem, operando uma radical mudança na percepção humana sobre a realidade -, Couchot investiga a TV e as imagens criadas pela televisão sob outros aspectos, por exemplo, como meio tecnológico que possui uma gramática e uma estética próprias, avaliando-a em relação aos outros meios de comunicação, como a fotografia e o cinema, e também seus efeitos sobre a percepção da realidade e sua ressonância sobre as artes.

Sem perder o foco da discussão, mas reforçando a idéia de que não podemos discutir um assunto tendo como referência apenas uma visão, antes de retornarmos ao filme creio ser importante acompanhar, mesmo que longa, uma das análises que Couchot faz da TV. Em A Tela Eletrônica, escreve:

A imagem reproduzida sobre o fundo de uma câmera eletrônica não é, na realidade, diferente, sob um ponto de vista morfogenético, daquela projetada sobre uma película fotográfica ou sobre um filme. Ela ainda permanece sendo a emanação luminosa de uma realidade preexistente captada e organizada pela objetiva da câmera escura. Em contrapartida, o modo de registro dessa imagem muda completamente. Contrariamente à fotografia e ao cinema nos quais o plano inteiro da imagem projetada sobre a película é gravada de uma só vez e de maneira permanente (após sua fixação), a televisão opera primeiramente por análise linear [...]. Nenhum prazo separa o momento da tomada da cena, próprio à imagem cinematográfica, e o momento de sua representação. A partir daí, existe concomitância entre o tempo de gravação e o de representação. Neste sentido, a televisão faz "mais" do que representar, ela torna presente. Ela coloca o observador, instantaneamente e independentemente da distância, em contato visual com a realidade ${ }^{8}$.

Continuando a discussão do filme e das mudanças que os meios tecnológicos provocam, podemos relacionar a análise que Couchot ${ }^{9}$ apresenta da sobreapresentação televisiva - que faz coincidir o tempo da realidade captada no seu desenrolar, o tempo da imagem e o do observador - com a história de Chance. Seu tempo é o tempo presente. Ele não tem passado, só presente. E vive esse presente, vive o acontecimento dado pela tela da TV, vive a aderência

8. COUCHOT, op. cit.,

p. 81-82.

9. Ibid., p. 82. 


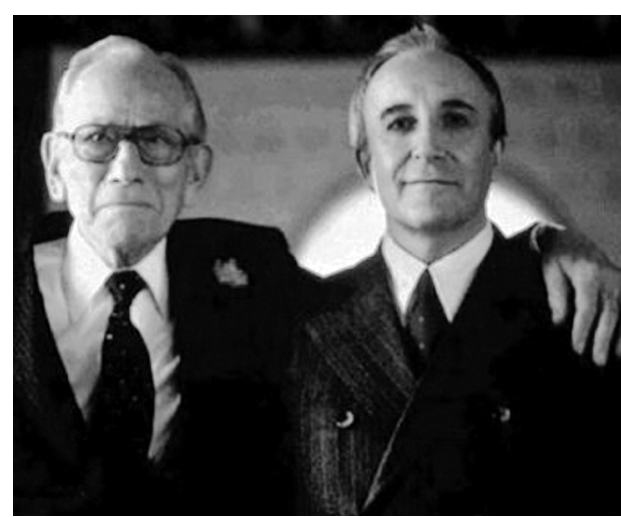

Divulgação ao tempo presente. Acontecimento que, segundo Couchot, faz do espectador uma espécie de mípe temporário. Este autor se aproxima de Sartori quando diz que "a sobreapresentação televisiva favorece a perda da memória e paralisa a antecipação reflexiva"10; porém, na seqüência, aponta para uma outra mudança que a televisão produz em nossa percepção: a capacidade aguda para captar uma multiplicidade de acontecimentos paralelos e caóticos. Chance, não por acaso, embora não refletisse sobre o que estava acontecendo nem sobre o que falava, captava todos os acontecimentos apresentados pela tela eletrônica, e até mesmo se deixava captar pela tele-visão para responder as perguntas que lhes eram feitas. Ironicamente, no filme, sua genialidade era fruto dessa aderência ao presente e também de sua paralisia reflexiva.

Antes de partirmos para o segundo momento das reflexões, é interessante uma outra aproximação entre Sartori e Couchot. Não uma unanimidade de pensamentos, mas a aproximação de uma mesma questão: a independência do meio.

Sartori, em suas reflexões sobre a televisão, coloca como essencial o fato de entendermos que, enquanto nos preocupamos com os que controlam os meios, não nos damos conta de que escapou de nosso controle o próprio meio. E Couchot, ao analisar o olhar reticulado, nos chama a atenção para a tela que se impõe por ela mesma. Para ele, a televisão se aproxima do rádio e produz efeitos comparáveis no domínio da imagem, ou seja, a não-hierarquia, o acaso, o acidente, a heterogeneidade. Daí, segundo o autor, "a vocação da imagem eletrônica de ser combinada com ambientes variados, confrontadas com outros objetos, a outras imagens, de ser mergulhada em situações inabituais para uma imagem"11. Para finalizar esta primeira parte, importa retomar o início do exercício, ou seja, o de entender os avanços dos meios tecnológicos para além do bem ou do mal, mas como transformadores, entre outras mutações antropológicas, da percepção humana sobre a realidade. A televisão, nos dizeres de Couchot, "confere ao sujeito-nós aptidões perceptivas que nem a foto nem o cinema, menos ainda a imagem pintada, podiam lhe dar. O olhar daí em diante reticulado pode se projetar em todo lugar e se livrar de toda distância" ${ }^{\prime 2}$.

É claro que estes não são os

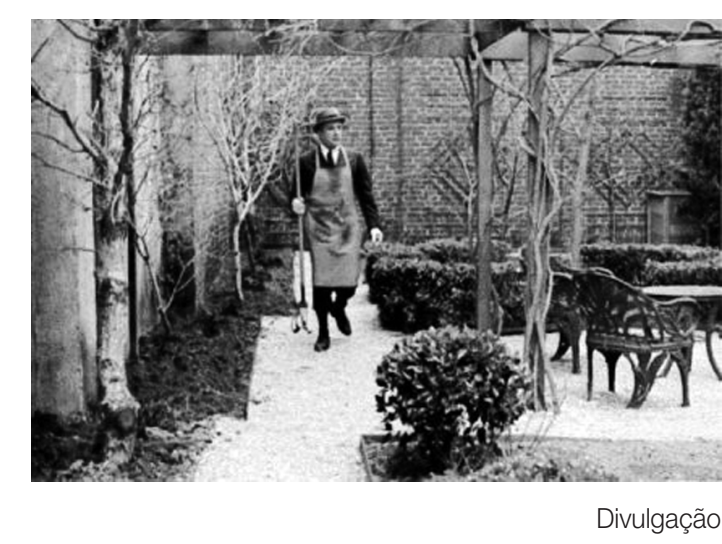


transformações que o desenvolvimento das tecnologias provocam na antropologia humana. Sartori e Couchot foram trazidos como exemplos de análises sobre a televisão e como indicação para discussão sobre meios de comunicação, alunos e sala de aula, sem esquecer, no entanto, que também estamos expostos aos meios e a essas mutações.

\section{DA SALA DOS PROFESSORES PARA A SALA DE AULA: SOBRE TRANSFORMAÇÕES TECNOLÓGICAS E ANTROPOLÓGICAS}

Partindo do filme e dos textos de Sartori e de Couchot, a segunda parte do exercício pode ser a de levar à sala de aula as pesquisas sobre meios de comunicação de massa, transformações tecnológicas, convergências entre meios de comunicação e artes e mutações antropológicas, bem como os debates que o surgimento de cada meio suscitou no momento de seu aparecimento na história.

É sabido que os progressos tecnológicos são quase sempre seguidos de debates, ou porque provocam inseguranças e temores, ou porque são considerados, sem nenhuma avaliação crítica, como progressos da humanidade. Sabemos, no entanto, que essas afirmações precisam ser discutidas e compreendidas de maneira mais ampla. Se a primeira afirmação pode ser entendida porque as inovações incomodam, porque mudam as situações em que a sociedade humana está constituída, a segunda pede uma revisão, uma vez que nem todas as transformações tecnológicas foram recebidas sem ressalvas.

Sobre tais questões, é interessante acompanharmos as análises de Giovanni Sartori, quando escreve:

Do ponto de vista histórico, a inovação mais combatida foi aquela da máquina e do maquinário industrial [...]. Em comparação com a revolução industrial, a invenção da imprensa e o progresso das comunicações não encontraram hostilidades relevantes; aliás, quase sempre foram aplaudidos e acompanhados por previsões eufóricas. Quando de sua descoberta, o jornal, o telégrafo, o telefone e o rádio [...], quase todos os inventos foram saudados como "progressos" positivos para a divulgação da informação, das idéias e da cultura. Neste contexto as objeções e os medos não atacaram os instrumentos, mas o seu conteúdo ${ }^{13}$.

Embora o interesse esteja concentrado nos meios de comunicação de massa, a primeira pesquisa pode ser mais geral: sobre as inovações tecnológicas ocorridas desde o final do século XIX, quando a industrialização trouxe consigo, além de uma proliferação de inventos, a urbanização, o crescimento populacional, as mudanças dos meios de transportes e o choque inicial, tanto físico como perceptível do novo ambiente que se instalava e que dura até os dias atuais. Mudanças que transformariam também a estrutura da experiência humana. $\mathrm{Na}$ análise de Ben Singer ${ }^{14}$ sobre a modernidade do início do século XX, o indivíduo se defrontava com uma nova intensidade de estímulos
13. SARTORI, op. cit. p. 16-17.

14. SINGER, Ben. Modernidade, hiperestímulo e o início do sensacionalismo popular. In: SINGER, Ben O cinema e a invenção da vida moderna. São Paulo: Cosac\&Naify, 2004. 
sensoriais. Aprofundando um pouco mais a pesquisa, vale a pena mapear as revoluções tecnológicas processadas entre o final da Primeira Guerra e o final da Segunda. Entre as guerras, o estudo do rádio pode ser o primeiro a ser analisado pelas mudanças que provocou nos modos de percepção do tempo e do espaço. De acordo com Couchot, de todas as evoluções que participaram do campo tecnestésico, a radiodifusão, por exemplo, "faz passar o som do espaço acústico ao espaço hertziano: tudo se passa como se de repente o ouvido estivesse afetado por certas qualidades do olho. A audição passa a levar mais longe e mais diretamente do que a vista" ${ }^{15}$. Em seguida, ou paralelamente ao estudo do rádio - uma vez que a idéia aqui não é a de um estudo da história dos meios, mas como as revoluções nas tecnologias de comunicação modificam as estruturas perceptivas do homem -, podemos estudar o cinema. Cinema que além de entretenimento, segundo Couchot, "não é somente a imagem em movimento, é o olho em movimento, uma certa figuração da mobilidade e da velocidade [...]. Na projeção de um filme, a contemplação é incessantemente interrompida pela transformação das imagens"16, apenas para citar alguns exemplos de transformações. Apesar de o foco de estudo serem as mutações que a TV provocou na estrutura humana, nada nos impede de avançar no assunto até chegarmos ao computador, uma vez que tanto o computador como a televisão têm em comum o desenvolvimento de uma técnica: o tubo a vácuo.

Se ligar a TV é, antes de tudo, se conectar com o lugar da emissão da imagem (o canal) no momento em que ele se constitui, é estar presente ao próprio nascimento da imagem, como escreveu Couchot, como e qual seria nossa análise do filme $O$ Show de Truman, em que o personagem vive numa comunidade sem saber que todas as suas "ações cotidianas são cenarizadas e transmitidas a um público mundial, em tempo real, por ubíquas câmeras de televisão, controladas por técnicos e um diretor de programação"17? Essa já é uma outra história, mas, e ao mesmo tempo, continuação do debate.

15. COUCHOT, op. cit. p. 69

16. Ibid., p. 73

17. SODRÉ, Moniz. Antropológica do espelho: uma teoria da comunicação linear e em rede. Petrópolis: Vozes, 2002. p. 26
Resumo: A proposta da Videografia é, a partir do filme Muito Além do Jardim, refletir sobre as transformações tecnológicas e as mudanças que as tecnologias têm produzido no homo sapiens, apresentando as análises que alguns teóricos fazem sobre a televisão. No caso, os autores Giovanni Sartori e Edmond Couchot.

Palavras-chave: cinema, novas tecnologias, realidades ampliadas, antropogenética, televisão.
Abstract: This Videography's proposal is, having as basis the motion picture Being There and some theorists' analysis about television, to reflect on the technological transformations and changes that technologies have being producing in the homo sapiens. The theorists introduced are Giovanni Sartori and Edmond Couchot.

Keywords: cinema, new technologies, reality amplifies, antropogenética, television. 